\title{
The Effect of Alginate, Chitosan, and Nano Chitin as Encapsulation Materials of $L$. Casei Probiotic Bacteria
}

\author{
Djaenudin $^{1,2 *}$, Endang Saepudin², and Muhamad Nasir ${ }^{1}$ \\ ${ }^{1}$ Research Unit For Clean Technology, Indonesian Institute of Sciences \\ Indonesia \\ ${ }^{2}$ Department of Chemistry, University of Indonesia \\ Indonesia \\ * Corresponding author's email: aburizki [AT] yahoo.com
}

\begin{abstract}
Alginate, nano chitin, and chitosan polymers can be used to protect the Lactobacillus casei from gastric conditions. The goal of this study was to determine the effect of alginate, nano chitin, and chitosan as encapsulation materials of L. casei on their survivability in simulated gastric fluid (SGF). The encapsulation process in this study was carried out by the extrusion method. The resulted beads were soaked in SGF ( $\mathrm{pH}$ of 1.2 and 3) for 1 and 60 min at $37^{\circ} \mathrm{C}$. In SGF pH 1.2 for $60 \mathrm{~min}$, the survivability of L.casei in all variations of the experiment was $0 \%$ except those encapsulated from alginate (1\%), nano chitin (0.2\%), and chitosan (0.2) \% of 75.35\%. In SGF pH 3 for 60 min, the survivability of L.casei was $0 \%$ for beads unencapsulation and encapsulation made from alginate, while the highest survivability of L.casei was $81.22 \%$ obtained in various encapsulation experiments using alginate (1\%), nano chitin $(0.2 \%)$, and chitosan (0.2\%). The addition of nano chitin or chitosan to L.casei encapsulation material can increase the survivability of L.casei, also showed that the combination of alginate, nano chitin, and chitosan in the encapsulated material significantly increased the survivability of L.casei at SGF pH 1.2 and 3.
\end{abstract}

Keywords--- Encapsulation, L.casei, alginate, nano chitin, chitosan

\begin{abstract}
Alginate Based Encapsulation Material
Alginate is the most frequently used matrix for immobilizing probiotics, this is due to its economic efficiency and biocompatibility [1]. Some of the advantages of alginate beads are their resistance to acidic environments [2]. However, alginate porosity can be a drawback in its application as a probiotic drink. The presence of pores provides a way for gastric acid to enter the microbeads so that it has a great chance to kill the probiotics encapsulated by the alginate. Therefore, the combination of alginate with polymers or other foodstuffs is needed to overcome this porosity [3, 4].

Alginate is a natural polymer that has been successfully applied as a $\mathrm{pH}$-sensitive material for the encapsulation of probiotic bacteria [5]. Alginate is a polysaccharide extracted from algae consisting of various quantities and sequential distributions of $\beta$-D-mannuronic (M) and $\alpha-\mathrm{L}$ - guluronic acid (G) (copolymers containing MM, GG, and irregular sequences of $\mathrm{M}$ units. and $\mathrm{G}$ ) which can affect the functional properties of alginate as the encapsulation material [6]. When sodium alginate solution containing a cell suspension is poured into a calcium solution, the bound ions interact with other GG blocks to form a complex leading to gel formation and possible release of cells residing in the intestinal tract [1].
\end{abstract}

\section{INTRODUCTION}

\section{Chitosan-Based Encapsulation Material}

Treatment of chitin with an alkaline solution converts it to either completely or partially deacetylated chitosan. Chitosan can be defined as a natural, non-toxic biopolymer and a linear polysaccharide consisting of $\beta-1,4-G l c N A c$ and $\beta$ 1,4-GlcN. Chitosan is insoluble in water but dissolves in aqueous organic acid solutions [7]. Unlike chitin, chitosan is not a component in animal species and is rarely found in nature. Natural sources of chitin, including crab and shrimp shells, squid bone plates, and cuttlefish do not contain chitosan, however, fungi synthesize chitin and chitosan in their cell walls [7]. Chitosan is an important component of the cell wall of Zygomycetes [7]. Chitosan is also naturally found in the mycelia, stalks, and spores of Basidiomycetes, Ascomycetes, and Phycomycetes [8]. Chitosan from crustacean sources has a high molecular weight (MW) with low polydispersity, degrees of $\mathrm{N}$-acetylation (DA) below $20 \%$, and a solution viscosity of $1 \%$ from 500-1,700 cps. While mushroom chitosan has low MW with high polydispersity, DA lower than $15 \%$, and $1 \%$ solution viscosity than 10-15 cps[7]. Annually, approximately 150,000 tonnes of industrially usable chitosan is derived from the conversion of chitin which is obtained as a byproduct of seafood processing. Most of the chitosan is used in cosmetics, organic fertilizers, and food supplements [9]. Chitosan can be distinguished based on the number of acetylation units of D-glucosamine. Chitin contains more than $70 \%$ acetate units, while chitosan has less than $30 \%$ acetylation. With organic acids such as formic acid, acetic acid, and ascorbic acid, chitosan forms salts and consequently becomes water- 
soluble [7]. Chitosan contains three reactive functional groups, an amino or $\mathrm{N}$-acetamide group along with two primary and secondary hydroxyl groups at positions C-2, C-3, and C-6 respectively. The main difference between the structure and physicochemical properties of different chitosan is the amino- or $\mathrm{N}$-acetamide group [7]. The classification of chitosan can be carried out according to the residual $\mathrm{N}$-acetate fraction (FA), DA, polymerization level (DP), MW, MW distribution (PD or Polydispersity), and $\mathrm{N}$-acetylation pattern (PA) or sequence [10]. Chitosan offers great potential for applications in various industries due to its distinctive physicochemical characteristics such as biocompatibility, biodegradability, and low toxicity [7]. Figure 1 below showed the chemical structure of chitosan.

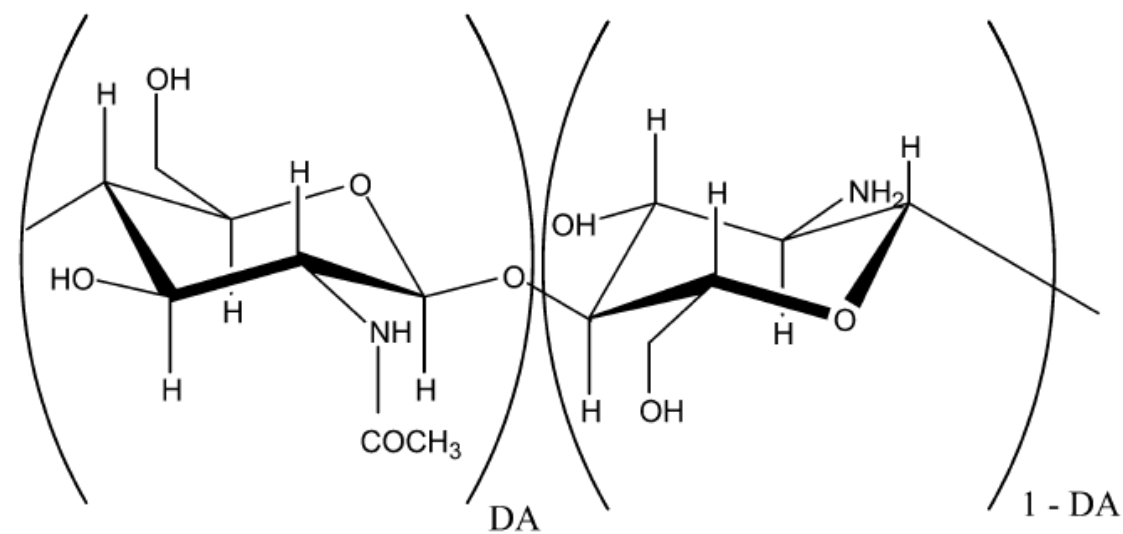

Figure 1. The structure of chitosan with a degree of acetylation (DA) [11]

Chitosan can form a gel with sodium alginate (non-toxic multivalent anion contraction) by ionic cross-linking [12]. The alginate beads coating and its efficiency in protecting probiotics have been extensively studied for several years. Previous studies have found that coating the alginate beads with chitosan has a significant effect on alginate stability, thereby increasing the viability of the encapsulated probiotics [4].

The researchers have encapsulated $L$. casei probiotics with extrusion techniques and carried out microbeads testing in SGF at $37^{\circ} \mathrm{C}[13,14]$. The results of the research showed that at $\mathrm{pH} 6.5$ (control), the viability of $L$. casei cells in SGF remained above $8 \log _{10} \mathrm{CFU} / \mathrm{g}$ after 2 hours of incubation at $37^{\circ} \mathrm{C}$ whether encapsulated or not. At $\mathrm{pH} 2$, no free cells survived after 2 hours incubation in SGF and the results showed that L. case $i$ was sensitive to SGF (pH 2). Under the same conditions ( $\mathrm{pH} 2,30 \mathrm{~min}$ ), the number of live cells of $L$. casei in alginate beads, and alginate-chitosan beads were 7.97, and 8.09 $\log _{10} \mathrm{CFU} / \mathrm{g}$, and with increasing times of up to $120 \mathrm{~min}$, the reduction of the two types of beads were $0.86 \log _{10} \mathrm{CFU} / \mathrm{g}$, and $0.71 \log _{10} \mathrm{CFU} / \mathrm{g}$, respectively. The viability of $L$. casei under acidic conditions indicated that there was a decrease in $\mathrm{CFU} / \mathrm{g}$ similar to bacteria at $\mathrm{pH} 2$ and 3. It was clear that the viability of encapsulated cells was significantly better than that of free cells after exposure to SGF ( $\mathrm{pH} 2$ ) and alginate beads [13]. The survival of probiotics was lower in gastric juice and decreased further as the incubation period increased. After $120 \mathrm{~min}$, the survival of free $L$. casei decreased from $2.51 \times 10^{11}$ to $1.1 \times 10^{3} \mathrm{CFU} / \mathrm{mL}$. However, the cell number of coated and uncoated encapsulated $L$. casei decreased to $6.3 \times 10^{7}$ and $6.2 \times 10^{6} \mathrm{CFU} / \mathrm{mL}$ respectively after $120 \mathrm{~min}$. In the case of $L$. casei, the survival of cells in both coated and uncoated beads was significantly $(\mathrm{P}<0.05)$ better than that of free cells and alginate-gelatinized starch with chitosan coating provided the best protection for both probiotics [14].

The alginate matrix, which consisted of an open lattice structure, forms porous beads and it was used to modify chitosan in a polyelectrolyte complex [15]. This approach was therefore employed here. The structure of chitosan was modified by cross-linking with alginate via ionic interaction between the carboxyl residues of alginate and the amino terminals of chitosan [15]. A conceptual representation of this was depicted in Figure 2. This complexation reduced the porosity of the alginate beads and decreases the leakage of the encapsulated substances. 


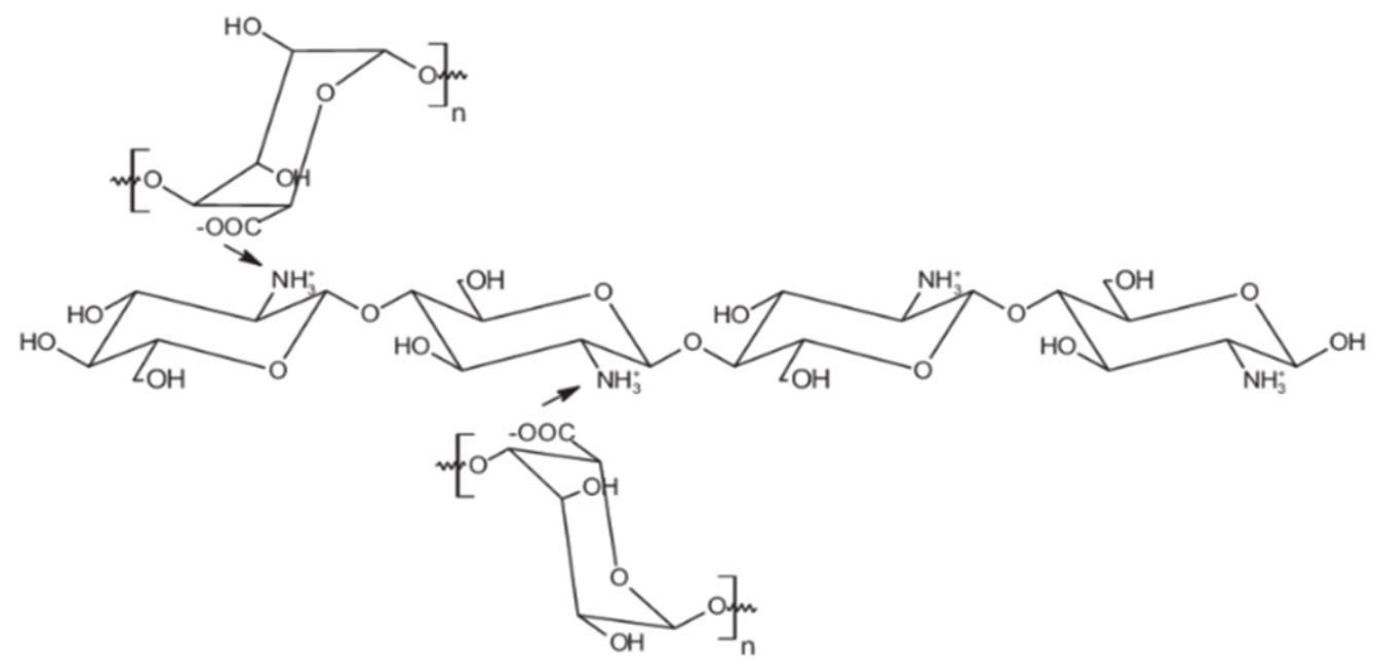

Figure 2. Chitosan-alginate cross-linking interaction [15]

\section{Nano chitin}

Chitin is a very important and abundant natural polysaccharide after cellulose. Chitin was first identified in 1884. Chitin occurs in nature as microfibril crystals to form compound structures in the arthropod exoskeleton or the cell walls of fungi and yeast. Although chitin is widespread until recently the main sources of chitin used commercially were crab shells and shrimp [7]. Chitin is tasteless, odorless, and insoluble in water, generally organic solvents, inorganic acids, and dilute bases. Chitin has antitumor, antimicrobial, antifungal properties, and can increase immune power[7]. Also, its biodegradable and nontoxic properties are considered to be used as a nutrient delivery system in the digestive system or encapsulation that can be applied with nanotechnology. The excess of food material at the nanometer scale affects its bioavailability and nutritional value [16].

\section{Equipments}

\section{EXPERIMENTAL SECTION}

Scanning Electron Microscopy (SEM) (JEOL JSM-IT300), Petri dishes (Normax), ose needles, beaker glass (Pyrex), measuring flask (Pyrex), Erlenmeyer, test tubes, stirring rods, funnels, spatulas, volume pipettes, micropipettes (Effendorf), watch glass, shaker incubator (CERTOMAT® BS-1), autoclaves (Tomy SX- 300), incubator (Memmert 854 Schwabach), Laminar Air Flow (ETL), refrigerators, wrap, aluminum foil, plastic vortex (Thermo), analytical balance, glass preparations, microscopes, $\mathrm{pH}$ meter (Horiba, Japan), hot plates, magnetic stirrers, syringe (Therumo) $22 \mathrm{G}$ (inner diameter $0.394 \mathrm{~mm}$ ), syringe $60 \mathrm{~mL}$, filter paper Whatman no. 40 .

\section{Materials}

The chemicals used were Na-alginate 1\% (HIMEDIA® REF MB-114-100G), chitosan 0.2\% (Sigma Aldrich PCode: 101729402), $\mathrm{CaCl}_{2}$ Solution $32 \mathrm{~g} / \mathrm{L}, \mathrm{NaCl}$ 0.2\% pH 1.5, Na-Citrate 1\%, MRSA (de Man Rogosa Sharpe Agar) (Merck, KGaA) and MRSB (de Man Rogosa Sharpe Broth) (Merck, KGaA).

\section{Procedure}

\section{Making sodium alginate solution containing the bacterial suspension}

The preparation of sodium alginate solution was first made of alginate solution $40 \mathrm{~mL}$ with a concentration of $1 \%$ (w/v) with distilled water. Then sterilized by autoclaving at $121^{\circ} \mathrm{C}$ for $15 \mathrm{~min}$. After the sodium alginate solution has been cooled to room temperature then $10 \mathrm{~mL}$ L. casei suspension was added.

\section{Making chitosan solution}

The preparation of the chitosan solutions was made with a concentration of chitosan $0.2 \%$ (w/v). $0.2 \mathrm{~g}$ chitosan was dissolved in a $100 \mathrm{~mL}$ acetic acid solution (1\% (v/v); $\mathrm{pH} 3.1) \mathrm{pH}$ chitosan solution was adjusted to pH $6 \mathrm{using} 1 \mathrm{M}$ $\mathrm{NaOH}$, then the solution was sterilized by autoclaving at $121^{\circ} \mathrm{C}$ for $15 \mathrm{~min}$.

\section{Encapsulation of L. casei using alginate-chitosan mixture}

The L. casei probiotic encapsulation method chosen was the extrusion method and the ionic gelation method. The extrusion method was chosen because besides using a simple tool in the form of a syringe, this method was also chosen to avoid extreme temperatures and pressures and from unfavorable environments such as low temperatures in the freeze- 
drying method, which can result in reduced bacterial viability[17]. While the choice of ionic gelation method was due to a simple process, did not use organic solvents, and can be controlled easily. While the principle of particle formation in the ionic gelation method was the occurrence of ionic interactions between the carboxylic anion $\left(\mathrm{COO}^{-}\right)$of the alginate monomer and the divalent cation $\left(\mathrm{Ca}^{+2}\right)$. Cross-linking occurs because a calcium ion replaced two sodium ions in alginate. This crosslinking structure caused limited molecular motion and inhibits the development of polymers in a medium [18]. The extrusion technique of microencapsulation was used [17]. Alginate beads were prepared as follows: sodium alginate was dissolved in distilled water $(1 \%, \mathrm{w} / \mathrm{v})$ and sterilized at $121^{\circ} \mathrm{C}$ for $15 \mathrm{~min}$. After cooling the alginate mixture, the cell suspension $(10 \mathrm{~mL})$ was mixed with the alginate mixture $(40 \mathrm{~mL})$ homogeneously and injected through a syringe into a sterilized $125 \mathrm{~mL} \mathrm{CaCl}_{2}(32 \mathrm{~g} / \mathrm{L})$ solution that was stirred continuously to form beads. The beads were allowed to harden for about $30 \mathrm{~min}$ in the $\mathrm{CaCl}_{2}$ solution and then washed with the distilled water. The beads were dried under controlled air flow and temperature $\left(4^{\circ} \mathrm{C}\right)$. Alginate-chitosan beads were prepared as follows: the wet state of alginate coated beads was soaked in $50 \mathrm{~mL}$ of chitosan solution $(0,2 \%, \mathrm{w} / \mathrm{v})$ and stirred for $15 \mathrm{~min}$ using a magnetic stirrer. The beads were dried under controlled air flow and temperature $\left(4^{\circ} \mathrm{C}\right)[20]$.

\section{Encapsulation of L. casei using alginate-nano chitin mixture}

Alginate beads were prepared as follows: sodium alginate was dissolved in distilled water (1\%, w/v) and sterilized at $121^{\circ} \mathrm{C}$ for $15 \mathrm{~min}$. After cooling the alginate mixture, the L. casei cell suspension $(5 \mathrm{~mL})$ and the nano chitin $(5 \mathrm{~mL} ; 0.2 \%(\mathrm{w} / \mathrm{v}))$ suspension were mixed with the alginate mixture $(40 \mathrm{~mL})$ homogeneously and injected through a syringe into sterilized $125 \mathrm{~mL} \mathrm{CaCl}_{2}(32 \mathrm{~g} / \mathrm{L})$ solution that was stirred continuously to form beads. The beads were allowed to harden for about $30 \mathrm{~min}$ in the $\mathrm{CaCl}_{2}$ solution and then washed with the distilled water. The beads were dried under controlled air flow and temperature $\left(4^{\circ} \mathrm{C}\right)[20]$.

\section{Encapsulation of L. casei using alginate-nano chitin-chitosan mixture}

Alginate beads were prepared as follows: sodium alginate was dissolved in distilled water (1\%, w/v) and sterilized at $121^{\circ} \mathrm{C}$ for $15 \mathrm{~min}$. After cooling the alginate mixture, the L. casei cell suspension ( $\left.5 \mathrm{~mL}\right)$ and the nano chitin $(5 \mathrm{~mL})$ suspension were mixed with the alginate mixture $(40 \mathrm{~mL})$ homogeneously and injected through a syringe into sterilized $125 \mathrm{~mL} \mathrm{CaCl}_{2}(32 \mathrm{~g} / \mathrm{L})$ solution that was stirred continuously to form beads. The beads were allowed to harden for about $30 \mathrm{~min}$ in the $\mathrm{CaCl}_{2}$ solution and then washed with the distilled water.

The beads were dried under controlled air flow and temperature $\left(4^{\circ} \mathrm{C}\right)$. Alginate-nano chitin-chitosan beads were prepared as follows: the wet state of alginate-nano chitin coated beads was soaked in $50 \mathrm{~mL}$ of chitosan solution $0,2 \%(\mathrm{w} / \mathrm{v})$ and stirred for $15 \mathrm{~min}$ using a magnetic stirrer. The beads were dried under controlled air flow and temperature $\left(4^{\circ} \mathrm{C}\right)[20]$.

\section{Surface morphoLogy and bead size determination}

The shape and surface characteristics were determined by scanning electron microscopy (SEM) using a gold sputter technique. The beads were vacuum-dried, coated with gold-palladium, and observed microscopically. The size of the L. casei loaded beads was measured with SEM.

\section{Viability of L. casei loaded in beads}

To determine the viable counts of the encapsulated L. casei, $1 \mathrm{~g}$ of beads were resuspended in $9 \mathrm{~mL}$ of sodium citrate $(1 \%)$ and stirred for 120 min using a magnetic stirrer. The complete release of bacteria from the beads in $120 \mathrm{~min}$ was previously assured by comparing the released number of cells from the beads. The colonyforming units (CFU/g) were determined by anaerobic plating on MRS agar plate and incubating at $37^{\circ} \mathrm{C}$ for 48 h. The plating procedures were carried out in triplicates. Non-encapsulated L. casei was enumerated in the MRS agar as control.

\section{Viability and survivability testing of L. casei probiotic processes}

Simulation gastric fluid (SGF) consisted of $0.2 \%$ Sodium chloride with a pH of 1.2 and 3 (adjusting the $\mathrm{pH}$ by adding $0.5 \mathrm{M}$ hydrochloric acid). $1 \mathrm{~g}$ beads (extrusion flow rate of $1 \mathrm{~mL} / \mathrm{min}$ with extruder voltage of 0 kilo Volt (kV)) were soaked in $9 \mathrm{~mL} \mathrm{SGF}$, incubated for 1 , and $60 \mathrm{~min}$ at a temperature of $37^{\circ} \mathrm{C}$. After that, it was filtered using Wattman 40 filter paper then soaked in $9 \mathrm{~mL}(1 \mathrm{~g} / 100 \mathrm{~mL})$ sterile sodium citrate solution with slow stirring at room temperature. Then sequential dilution was prepared to reach the number of cells that can be calculated by pouring a suspension technique that was spread on MRS Agar media. After that, it was incubated for 48 hours at $37^{\circ} \mathrm{C}$ [21]. The total colony can be calculated by the Total Plate Count (TPC) method. 


\section{RESULTS AND DISCUSSION} below.

The results of $L$. casei observations using SEM with a magnification of 10,000 times were shown in Figure 3

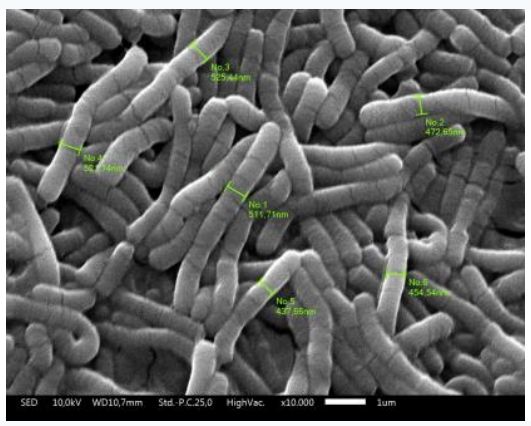

Figure 3. Observations of L. casei using SEM with a magnification of 10,000 times

Figure 3 showed that L. casei was a rod with a width of about $0.5 \mu \mathrm{m}$ and a length of $4 \mu \mathrm{m}$. The beads produced in the L. casei encapsulation process using variations of alginate, nano chitin, and chitosan were shown in Figure 4 below.

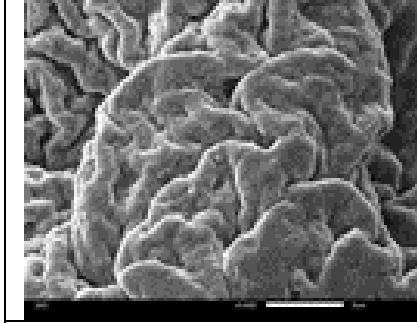

(a)

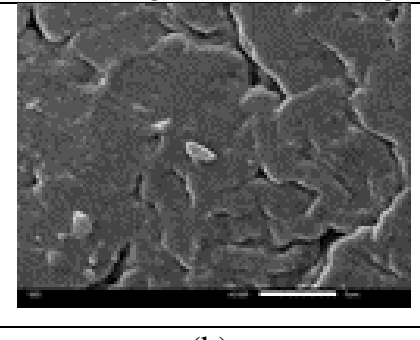

(b)

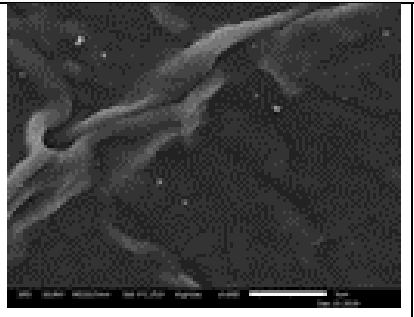

(c)

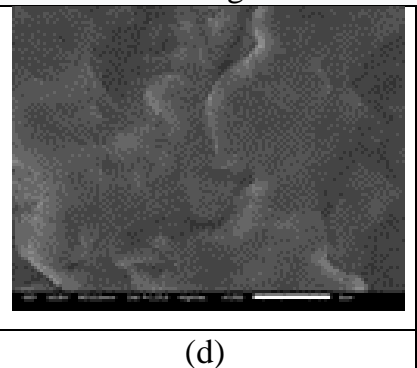

(d)

Figure 4. SEM analysis results of probiotics and beads were encapsulated before soaking in SGF, (a) ((Na-alginate $1 \%$ + L.casei $\left.)+\mathrm{CaCl}_{2}\right) ;\left(\right.$ b) $\left((\mathrm{Na}\right.$-Alginate $1 \%+$ L.casei $)+\mathrm{CaCl}_{2}+$ chitosan $\left.0,2 \%\right) ;($ c) $((\mathrm{Na}$-alginate $(1 \%)+$ L.casei + nano chitin $\left.0,2 \%)+\mathrm{CaCl}_{2}\right) ;\left(\right.$ d) $\left((\mathrm{Na}\right.$-alginate $1 \%+$ nano chitin $0,2 \%+$ L.casei $)+\mathrm{CaCl}_{2}+$ chitosan $\left.0,2 \%\right)$

Figure 4(a). showed that the beads formed by the alginate material produced a pore-rich surface. Meanwhile, the alginate beads coated with chitosan tend to have fewer pores, as shown in Figure 4(b). Meanwhile, the nano chitin mixed directly with alginate in the syringe tube produced a much smoother surface as shown in Figure 4(c). Figure 4(d) showed the surface of the beads made of nano chitin mixed directly with alginate in the syringe tube, then after forming the beads again coated with chitosan, the surface of the beads was much smoother and denser than Figure 4(a), (b) and (c). ). The beads morphology was shown in Figure 4(d) was the best beads. The beads that have been soaked in SGF pH 1.2 liquid were shown in Figure 5 below.

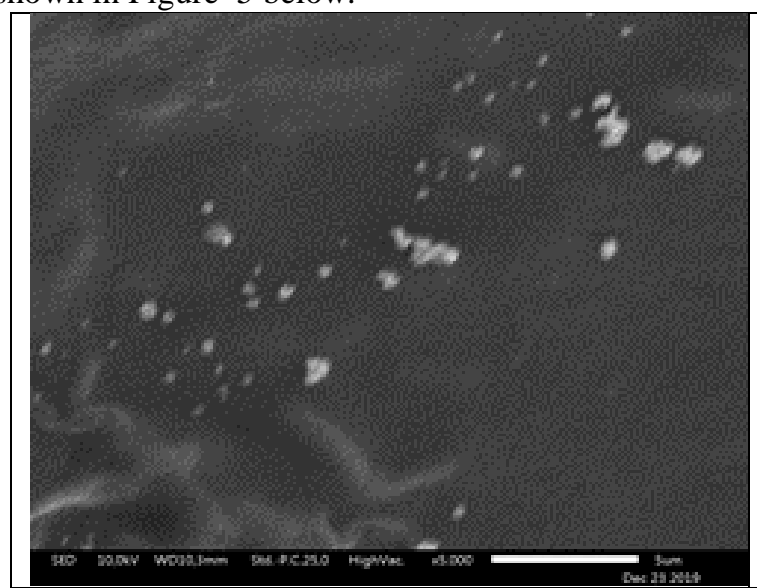

(a)

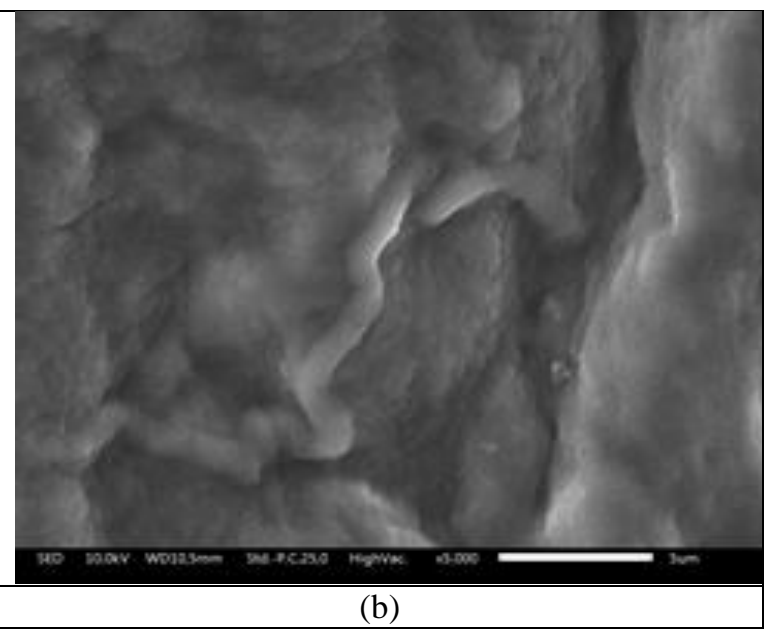

(b)

Figure 5. SEM analysis results of probiotics and encapsulated beads after soaking in $\mathrm{SGF}$ pH 1.2, (a) ((Na-alginate $(1 \%)+$ L.casei + nano chitin $\left.0,2 \%)+\mathrm{CaCl}_{2}\right) ;\left(\right.$ b) $\left((\mathrm{Na}\right.$-alginate $1 \%+$ nano chitin $0,2 \%+$ L.casei $)+\mathrm{CaCl}_{2}+\mathrm{chitosan}$ $0,2 \%)$ 
Figure 5 showed that the beads soaked in SGF pH 1.2 caused L.casei in the beads to start to push out the surface of the beads. The viability of A (free cell/unencapsulated), B (encapsulated using alginate 1\%), C (encapsulated using alginate $1 \%$, chitosan $0.2 \%$ ), D (encapsulated using alginate $1 \%$, nano chtin $0.2 \%$ ), E (encapsulated using alginate $1 \%$, nano chtin $0.2 \%$, and chitosan $0.2 \%$ ) at an extrusion voltage of $0 \mathrm{kV}$ and the extrusion flow rate of $1 \mathrm{~mL} / \mathrm{min}$ was shown in Figure 6 below.

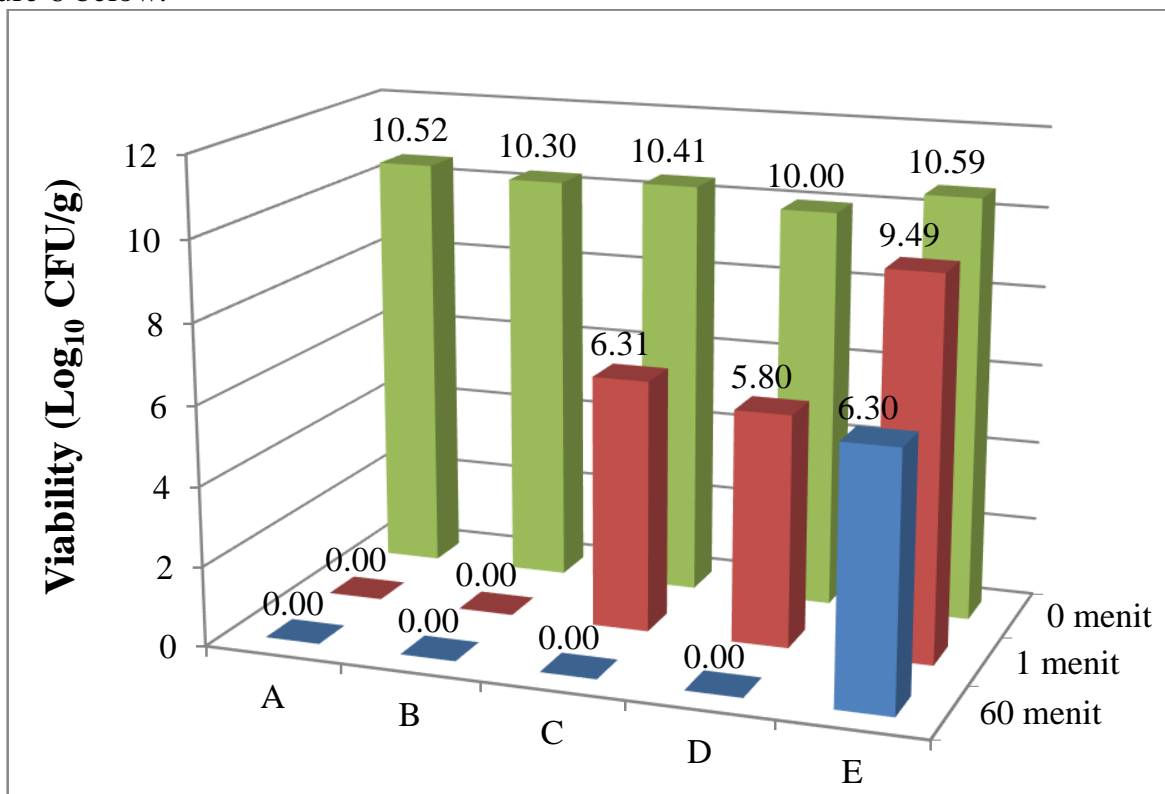

\section{Soaking Time in SGF pH 1.2}

Encapsulation Materials

Figure 6. Viability of L. casei before and after soaking in SGF pH 1.2

Figure 6 showed that the initial viability value of $L$. casei ranges from 10 to $10.59 \log _{10} \mathrm{CFU} / \mathrm{g}$. This value showed the viability that was quite feasible for the soaking process in SGF. Figure 6 showed that the viability value of $L$. casei was $0 \mathrm{CFU} / \mathrm{g}$, after soaking in SGF pH 1.2 for $1 \mathrm{~min}$. Meanwhile, the highest viability was achieved by beads made of a mixture of alginate-nano chitin-chitosan which was $9.49 \log _{10} \mathrm{CFU} / \mathrm{g}$. This indicated that L.casei cannot survive in SGF pH 1.2, either unencapsulated or encapsulated with alginate. The surface of the beads which were formed from alginate material still had a lot of pores so that SGF liquid can easily penetrate the inside of the beads and came into direct contact with $L$. case $i$ so that it was killed. The beads that were added with nano chitin and chitosan to the alginate beads tended to have a much tighter surface, thereby reducing the SGF liquid penetrating the inside of the beads. This happened because the nano chitin was mixed directly with the alginate in the syringe so that when the encapsulation process was formed, the nano chitin was physically trapped in the alginate which resulted in reduced alginate pores. While chitosan was added after the beads were formed by soaking the beads in a solution of chitosan, so that the surface of the beads was coated with chitosan which was an ionic bond between the amino group $-\mathrm{NH}_{3}{ }^{+}$of chitosan with the $\mathrm{COO}^{-}$carboxyl group of alginate [12]. This results in the pores of the alginate on the surface of the beads closed finely [22].

The viability value of $L$. casei was $0 \mathrm{Log}_{10} \mathrm{CFU} / \mathrm{g}$, after soaking in SGF pH 1.2 for $60 \mathrm{~min}$. This showed that L.casei cannot survive in SGF pH 1.2 for 60, both unencapsulated and encapsulated with alginate, alginate-nano chitin, and alginate-chitosan. Meanwhile, beads made from a mixture of alginate-nano chitin and coated with chitosan had a viability of $6.3 \log _{10} \mathrm{CFU} / \mathrm{g}$. This showed that the beads formed with alginate-nano chitin-chitosan showed advantages over alginate, alginate-nano chitin, and alginate-chitosan. The survivability of L.casei unencapsulation and encapsulation that had been soaked in SGF pH 1.2 for 1 min and 60 min was shown in Figure 7 below. 


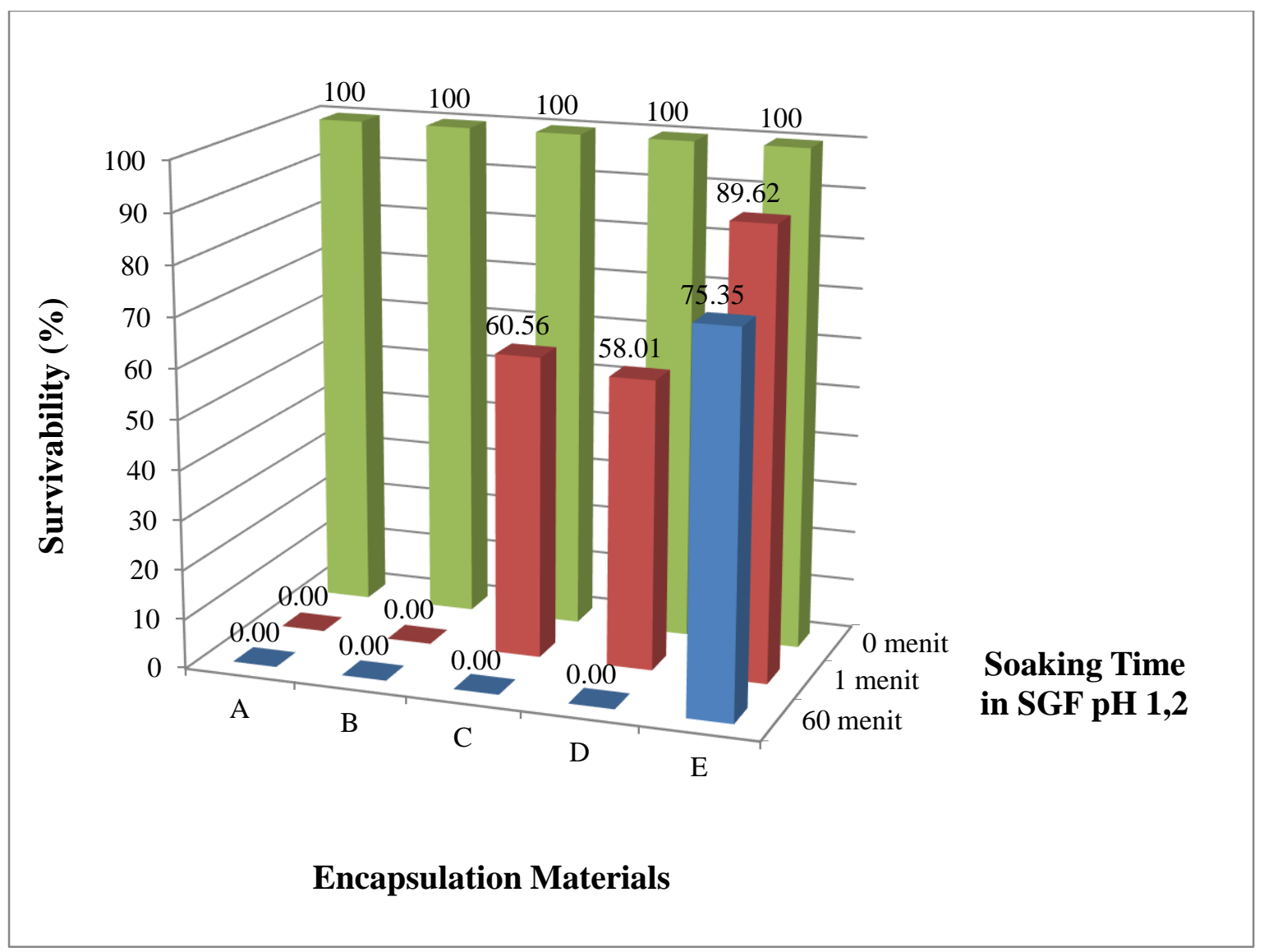

Figure 7. Survivability of L. casei before and after soaking in SGF pH 1.2

Figure 7 showed that the survivability value of $L$. case $i$ was $89.62 \%$ owned by the beads encapsulated using a mixture of alginate $(1 \%)$, nano chitin $(0.2 \%)$ then coated with chitosan $(0.2 \%)$ on the surface. The results of these experiments also showed that the combination of nano chitin and chitosan in the encapsulation material significantly increased the viability of L.casei.

In soaking the beads in SGF pH 1.2 for $60 \mathrm{~min}$, Figure 10 showed the survivability of L.casei in all variations of the experiment of $0 \%$ except those made from alginate $(1 \%)$, nano chitin $(0.2 \%)$, and chitosan $(0.2 \%)$ of $75.35 \%$. The results of these experiments also showed that the combination of nano chitin and chitosan in the encapsulation material significantly increased the viability of L.casei. The viability of L.casei unencapsulation and encapsulation that had been soaked in SGF pH 3 for 1 min and 60 min was shown in Figure 8 below. 


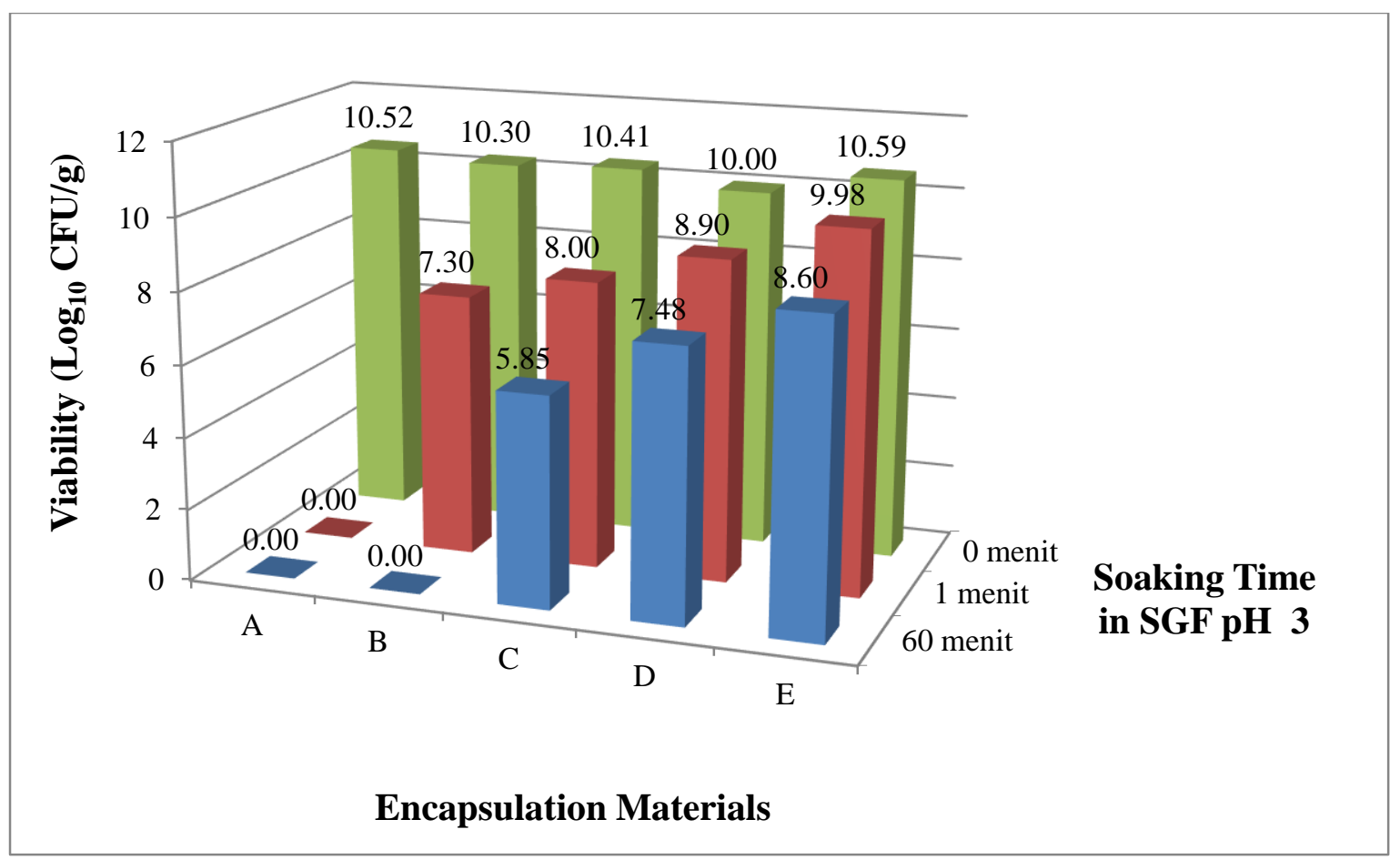

Figure 8. Viability of L. casei before and after soaking in SGF pH 3

Figure 8 showed that the viability value of L. casei was $0 \mathrm{CFU} / \mathrm{g}$, after soaking in SGF pH 3 for 1 min. This showed that unencapsulated L.casei cannot survive in SGF pH 3, while L. casei which had been encapsulated by alginate or a mixture of alginate, nano chitin, and chitosan still have high viability (above $8 \log _{10} \mathrm{CFU} / \mathrm{g}$ ) after experience soaking in SGF pH 3 for 1 min.

Figure 8 showed that the viability value of $L$. casei was $0 \mathrm{CFU} / \mathrm{g}$, after soaking in SGF pH 3 for 60 min. This indicated that L. casei cannot survive in SGF pH 3 for $60 \mathrm{~min}$, either unencapsulated or encapsulated with alginate. The surface of the beads which was formed from alginate material still has a lot of pores so that SGF liquid can easily penetrate the inside of the beads and come into direct contact with $L$. casei so that it was killed. The beads that were added with nano chitin and chitosan to the alginate beads tended to have a much tighter surface, thereby reducing the SGF liquid penetrating the inside of the beads. This happened because the nano chitin was mixed directly with the alginate in the syringe so that when the encapsulation process was formed, the nano chitin was physically trapped in the alginate which results in reduced alginate pores. Meanwhile, chitosan was added after the beads are formed by soaking the beads in a solution of chitosan so that the surface of the beads were coated with chitosan, which was an ionic bond between the $-\mathrm{NH}_{3}{ }^{+}$functional group of chitosan and the $\mathrm{COO}^{-}$functional group from alginate. This results in the pores of the alginate on the surface of the beads closed finely. The highest viability after soaking in SGF pH 3 for 60 min was achieved by beads made of a mixture of alginate-nano chitin-chitosan, which was $8.6 \log _{10} \mathrm{CFU} / \mathrm{g}$. The survivability of L.casei unencapsulation and encapsulation that has been soaked in SGF pH 3 for 1 min and 60 min was shown in Figure 9 below. 


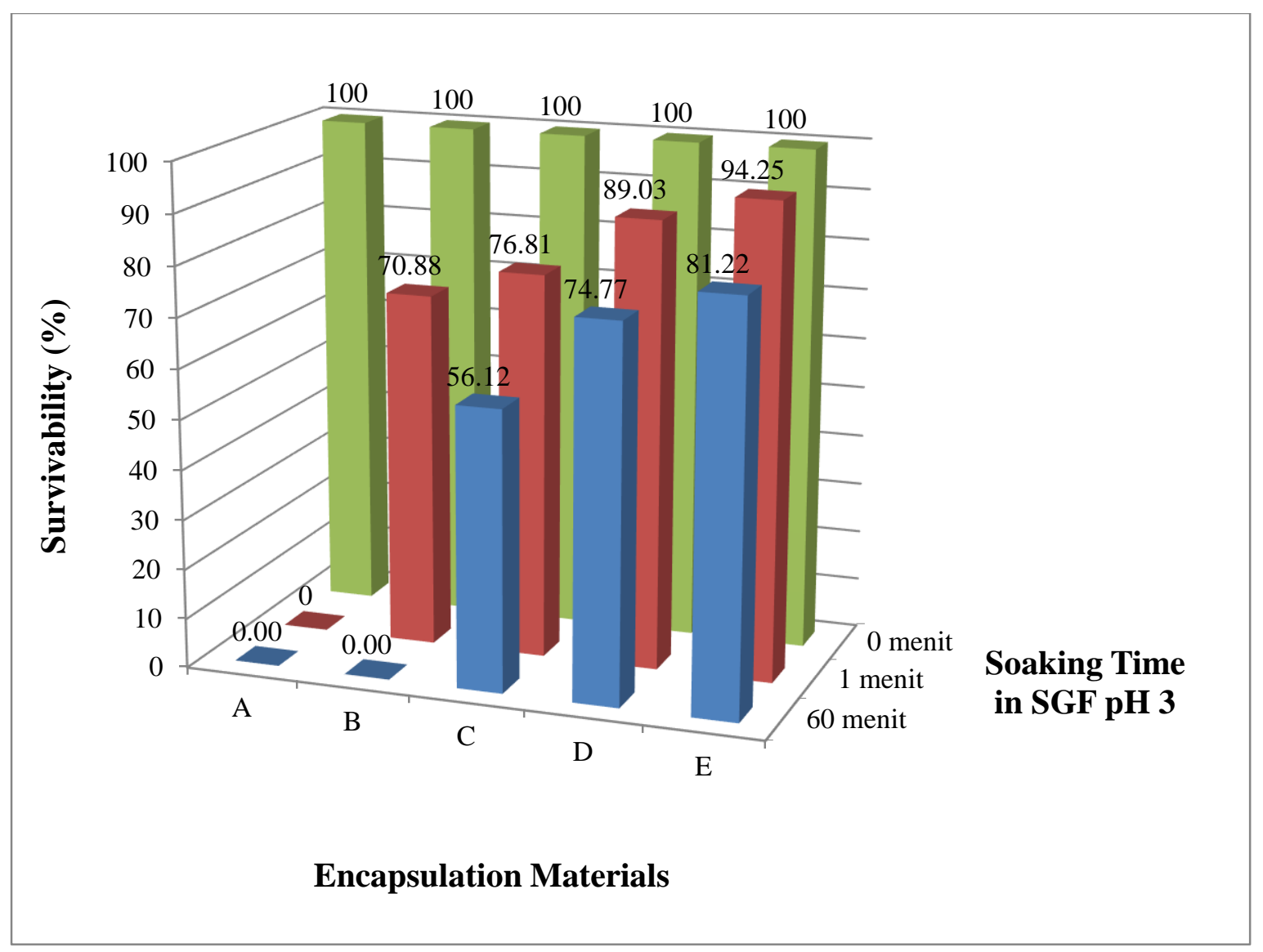

Figure 9. Survivability of L. casei before and after soaking in SGF pH 3

When soaking the beads in SGF pH 3 for 1 min, Figure 9 showed the survivability of L.casei unencapsulation of $0 \%$. Meanwhile, encapsulation by adding alginate, nano chitin, or chitosan can increase the survivability of L.casei. While the highest survivability of L.casei was $94.25 \%$ obtained in the variation of the encapsulation experiment using alginate (1\%), nano chitin $(0.2 \%)$, and chitosan $(0.2 \%)$. When soaking the beads in SGF pH 3 fluid for 60 min, Figure 9 showed the survivability of L.casei was $0 \%$ unencapsulation and encapsulation made from alginate. Meanwhile, encapsulation by adding alginate plus nano chitin or chitosan can increase the survivability of L.casei. While the highest survivability of L.casei, which was $81.22 \%$, was obtained in a variety of encapsulation experiments using alginate (1\%), nano chitin ( $0.2 \%)$, and chitosan $(0.2 \%)$. The results of these experiments indicated that the combination of chitosan and nano chitin in the encapsulated material can significantly increase the viability of L.casei. In SGF pH 3, the survivability of L.casei encapsulated using alginate $(1 \%)$, nano chitin $(0.2 \%)$, and chitosan $(0.2 \%)$ was higher than $\mathrm{pH} 1.2$. When nano chitin was mixed with alginate as an encapsulation material, when it was soaked in acid it shrank while the nano chitin was more bound to the alginate and can close the alginate pores so that the viability of L.casei was higher than without nano chitin. Chitosan can bind to the alginate chemically so that it can cover the pores of the alginate, but chitosan dissolved in acid so that when soaked in acid it caused chitosan to erode, but when the amount of chitosan was large it caused greater protective power so that it can increase the viability of L.casei.

\section{CONCLUSION}

By soaking the beads in SGF pH 1.2 for $60 \mathrm{~min}$, the survivability of L.casei in all variations of the experiment was $0 \%$ except those made from alginate $(1 \%)$, nano chitin $(0.2 \%)$, and chitosan $(0.2 \%)$ of $75.35 \%$. At the soaking of the beads in SGF pH 3 for 60 min, the survivability of L.casei was $0 \%$ for beads unencapsulation and encapsulation made from alginate, while the highest survivability of L.casei was $81.22 \%$ obtained in various encapsulation experiments using alginate. $(1 \%)$, nano chitin $(0.2 \%)$, and chitosan $(0.2 \%)$. The results showed that the addition of chitosan or nano chitin to L.casei encapsulation material increased the survivability of L.casei, also showed that the combination of alginate, nano chitin, and chitosan in the encapsulated material significantly increased the survivability of L.casei at SGF pH 1.2 and 3. In SGF pH 3, the survivability of L.casei was higher than $\mathrm{pH} 1.2$.

\section{ACKNOWLEDGEMENT}

The authors are grateful to the Indonesian Institute of Science for financial support through by research program. 


\section{CONFLICT OF INTEREST}

The authors declare that we have no known competing financial interests or personal relationships that could have appeared to influence the work reported in this paper.

\section{AUTHOR CONTRIBUTIONS}

Djaenudin conducted the experiment, the calculations, wrote and revised the manuscript. Endang Saepudin, and Muhamad Nasir conducted supervision. All authors agreed to the final version of this manuscript.

\section{REFERENCES}

[1] J. Li and S. Nie, 2019, The functional and nutritional aspects of hydrocolloids in foods, Food Hydrocoll., 53 (2016), 46-61, doi: 10.1016/j.foodhyd.2015.01.035.

[2] L. Agüeroa, D. Zaldivar-Silva, L. Pẽna, and M. L. Dias, 2017, Alginate microparticles as oral colon drug delivery device : A review, Carbohydr. Polym., 168, 32-43, doi: 10.1016/j.carbpol.2017.03.033.

[3] N. H. Khan, D. R. Korber, N. H. Low, and M. T. Nickerson, 2013, Development of extrusion-based legume protein isolate-alginate capsules for the protection and delivery of the acid sensitive probiotic, Bifidobacterium adolescentis, Food Res. Int., 54 (1), 730-737, doi: 10.1016/j.foodres.2013.08.017.

[4] H. Gandomi, S. Abbaszadeh, A. Misaghi, S. Bokaie, and N. Noori, 2016, Effect of chitosan-alginate encapsulation with inulin on survival of Lactobacillus rhamnosus GG during apple juice storage and under simulated gastrointestinal conditions, LWT - Food Sci. Technol., doi: 10.1016/j.lwt.2016.01.064.

[5] P. Allan-Wojtas, L. T. Hansen, and A. T. Paulson, 2008, Microstructural studies of probiotic bacteria-loaded alginate microcapsules using standard electron microscopy techniques and anhydrous fixation $\$, L W T, 41,101-$ 108, doi: 10.1016/j.lwt.2007.02.003.

[6] J. Burgain, C. Gaiani, M. Linder, and J. Scher, 2011, Encapsulation of probiotic living cells: From laboratory scale to industrial applications, J. Food Eng., 104 (4), 467-483, 2011, doi: 10.1016/j.jfoodeng.2010.12.031.

[7] F. Liaqat and R. Eltem, 2018, Chitooligosaccharides and their biological activities: A comprehensive review, Carbohydr. Polym., 184 (June 2017), 243-259, doi: 10.1016/j.carbpol.2017.12.067.

[8] A. R. Logesh, K. A. Thillaimaharani, K. Sharmila, M. Kalaiselvam, and S. M. Raffi, 2012, Production of chitosan from endolichenic fungi isolated from mangrove environment and its antagonistic activity, Asian Pac. J. Trop. Biomed., 2(2), 140-143, doi: 10.1016/S2221-1691(11)60208-6.

[9] J. G. Fernandez and D. E. Ingber, 2014, Manufacturing of Large-Scale Functional Objects Using Biodegradable Chitosan Bioplastic a, 1-7, doi: 10.1002/mame.201300426.

[10] B. B. Aam, E. B. Heggset, A. L. Norberg, M. Sø, K. M. Vå, and V. G. H. Eijsink, 2010, Production of chitooligosaccharides and their potential applications in medicine, Mar. Drugs, 8, 1482-1517, doi: $10.3390 / \mathrm{md} 8051482$.

[11] A. Tolaimate, J. Desbrieres, M. Rhazi, and A. Alagui, 2003, Contribution to the preparation of chitins and chitosans with controlled physico-chemical properties, Polymer (Guildf)., 44, 7939-7952, doi: 10.1016/j.polymer.2003.10.025.

[12] R. M. Lucinda-silva, H. Regina, N. Salgado, and R. Cesar, 2010, Alginate - chitosan systems : In vitro controlled release of triamcinolone and in vivo gastrointestinal transit, Carbohydr. Polym., 81, 260-268, doi: 10.1016/j.carbpol.2010.02.016.

[13] X. Y. Li, X. G. Chen, Z. W. Sun, H. J. Park, and D.-S. Cha, 2011, Preparation of alginate chitosan/carboxymethyl chitosan complex microcapsules and application in Lactobacillus casei ATCC 393, Carbohydr. Polym., 83 (4), 1479-1485, doi: 10.1016/j.carbpol.2010.09.053.

[14] M. Ali, K. Zanjani, and B. Ghiassi, 2014, Microencapsulation of probiotics by calcium alginate-gelatinized starch with chitosan coating and evaluation of survival in simulated human gastro-intestinal condition, Iran. J. Pharm. Res., 13 (3), 843-852.

[15] L. A. Nnamonu, R. Sha'Ato, and I. Onyido, 2012, Alginate Reinforced Chitosan and Starch Beads in Slow Release Formulation of Imazaquin Herbicide-Preparation and Characterization, Mater. Sci. Appl., 03 (08), 566-574, doi: 10.4236/msa.2012.38081.

[16] G. M. Raghavendra, J. Jung, D. Kim, and J. Seo, 2016, Microwave-assisted antibacterial chitosan-silver nanocomposite films, Int. J. Biol. Macromol., 84, 281-288, doi: 10.1016/j.ijbiomac.2015.12.026.

[17] D. Kavitake, S. Kandasamy, and P. Bruntha, 2018, Recent developments on encapsulation of lactic acid bacteria as potential starter culture in fermented foods - A review, Food Biosci., 21 (June 2017),. 34-44, doi: 10.1016/j.fbio.2017.11.003.

[18] E. Mardliyati, S. El Muttaqien, and D. R. Setyawati, 2012, Sintesis nanopartikel kitosan- trypoly phosphate dengan metode gelasi ionik : pengaruh konsentrasi dan rasio volume terhadap karakteristik partikel, Pros. Pertem. Ilm. Ilmu Pengetah. dan Teknol. Bahan, 90-93.

[19] W. Krasaekoopt, B. Bhandari, and H. Deeth, 2003, Evaluation of encapsulation techniques of probiotics for yoghurt, Int. Dairy J., 13 (1), 3-13, doi: 10.1016/S0958-6946(02)00155-3.

[20] O. Sandoval-Castilla, C. Lobato-Calleros, H. S. García-Galindo, J. Alvarez-Ramírez, and E. J. Vernon-Carter, 
2010, Textural properties of alginate - pectin beads and survivability of entrapped L. casei in simulated gastrointestinal conditions and in yoghurt, Food Res. Int., 43 (1),. 111-117, doi: 10.1016/j.foodres.2009.09.010.

[21] S. Woraharn, C. Chaiyasut, B. Sirithunyalug, and J. Sirithunyalug, 2010, Survival enhancement of probiotic Lactobacillus plantarum CMU-FP002 by granulation and encapsulation techniques, African J. Microbiol. Res., 4 (20), 2086-2093.

[22] P. Kanmani, R. S. Kumar, N. Yuvaraj, K. A. Paari, V. Pattukumar, and V. Arul, 2011, Effect of cryopreservation and microencapsulation of lactic acid bacterium Enterococcus faecium MC13 for long-term storage, Biochem. Eng. J., 58-59, 140-147, doi: 10.1016/j.bej.2011.09.006. 